\title{
Acute Hemodynamic Effects of Adaptive Servo-Ventilation in Patients With Heart Failure
}

\author{
Shiro Yamada, MD; Mamoru Sakakibara, MD, PhD; Takashi Yokota, MD, PhD; \\ Kiwamu Kamiya, MD; Naoya Asakawa, MD; Hiroyuki Iwano, MD, PhD; \\ Satoshi Yamada, MD, PhD; Koji Oba, PhD; Hiroyuki Tsutsui, MD, PhD
}

\begin{abstract}
Background: Adaptive servo-ventilation (ASV) improves cardiac function in patients with heart failure (HF). We compared the hemodynamics of control and HF patients, and identified the predictors for acute effects of ASV in HF.

Methods and Results: We performed baseline echocardiographic measurements and hemodynamic measurements at baseline and after $15 \mathrm{~min}$ of ASV during cardiac catheterization in 11 control and $34 \mathrm{HF}$ patients. Heart rate and blood pressure did not change after ASV in either the control or HF group. Stroke volume index (SVI) decreased from $49.3 \pm 7.6$ to $41.3 \pm 7.6 \mathrm{ml} / \mathrm{m}^{2}$ in controls $(P<0.0001)$ but did not change in the HF patients (from $34.8 \pm 11.5$ to $\left.32.8 \pm 8.9 \mathrm{ml} / \mathrm{m}^{2}, \mathrm{P}=0.148\right)$. In the univariate analysis, pulmonary capillary wedge pressure (PCWP), mitral regurgitation (MR)/left atrial (LA) area, E/A, E/e', and the sphericity index defined by the ratio between the short-axis and long-axis dimensions of the left ventricle significantly correlated with \% change of SVI from baseline during ASV. PCWP and MR/LA area were independent predictors by multivariate analysis. Moreover, responders (15 of $34 \mathrm{HF}$ patients; 44\%) categorized by an increase in SVI showed significantly higher PCWP, MR, and sphericity index.
\end{abstract}

Conclusions: Left ventricular structure and MR, as well as PCWP, could predict acute favorable effects on hemodynamics by ASV therapy in HF patients. (Circ $J$ 2013; 77: 1214-1220)

Key Words: Adaptive servo-ventilation; Heart failure; Hemodynamics; Mitral regurgitation; Remodeling

$\mathbf{S}$ leep-disordered breathing (SDB), including central sleep apnea (CSA) with Cheyne-Stokes respiration (CSR), is common in patients with heart failure (HF). ${ }^{1}$ It causes repeated episodes of hypoxia, leading to activation of the sympathetic nervous system, which may be associated with adverse cardiac events such as fatal ventricular arrhythmias and sudden cardiac death. ${ }^{2}$ Adaptive servo-ventilation (ASV) is a novel therapy that provides positive expiratory airway pressure and inspiratory pressure support, automatically adjusts its settings according to analysis of the patient's breathing, and maintains ventilation at $90 \%$ of running a 3-min reference period. ASV has been successfully used for treating CSA and CSR in patients with HF. ${ }^{3-8}$ Previous studies have demonstrated that in HF patients with CSR, wearing the mask during $\mathrm{ASV}$ is more comfortable for the patient, ${ }^{5}$ and has greater effects on reducing the apnea-hypopnea index than continuous positive airway pressure (CPAP). ${ }^{9,10}$ Moreover ASV may not only normalize the pattern of respiration and improve the qual- ity of sleep, but also stabilize sympathetic nerve activity..$^{8,11}$ These findings suggest that ASV may provide greater benefit and superior outcomes in HF patients with SDB compared with CPAP.

\section{Editorial p1148}

ASV could improve the left ventricular ejection fraction (LVEF), as a surrogate maker of cardiac function, ${ }^{5,7}$ plasma brain-type natriuretic peptide (BNP) level, ${ }^{7,8}$ or exercise tolerance. ${ }^{7}$ Furthermore, its efficacy could be recognized regardless of the severity of SDB. ${ }^{12,13}$ ASV itself may have direct favorable effects on cardiac hemodynamics by decreasing the left ventricular (LV) preload and afterload. In patients with acute pulmonary edema, a few studies have shown that noninvasive positive-pressure ventilation (NPPV), including CPAP or bilevel NPPV, reduced the need for tracheal intubation and mechanical ventilation ${ }^{14,15}$ by improving hypoxemia, decreasing

Received August 21, 2012; revised manuscript received November 25, 2012; accepted December 26, 2012; released online January 30, 2013 Time for primary review: 15 days

Department of Cardiovascular Medicine, Hokkaido University Graduate School of Medicine, Sapporo (Shiro Y., M.S., K.K., N.A., H.I., Satoshi Y., H.T.); Translational Research and Clinical Trial Center, Hokkaido University Hospital, Sapporo (K.O.), Japan; and Department of Biomedical Sciences, University of Copenhagen, Copenhagen (T.Y.), Denmark

Mailing address: Mamoru Sakakibara, MD, PhD, Department of Cardiovascular Medicine, Hokkaido University Graduate School of Medicine, Kita 15, Nishi 7, Kita-ku, Sapporo 060-8638, Japan. E-mail: mike.s@ninus.ocn.ne.jp

ISSN-1346-9843 doi:10.1253/circj.CJ-12-1088

All rights are reserved to the Japanese Circulation Society. For permissions, please e-mail: cj@j-circ.or.jp 


\begin{tabular}{|c|c|c|c|}
\hline & Control $(n=11)$ & HF $(n=34)$ & $P$ value \\
\hline Age (years) & $61.6 \pm 11.1$ & $57.3 \pm 14.5$ & 0.365 \\
\hline Gender (M/F) & $6 / 5$ & $26 / 8$ & 0.251 \\
\hline \multicolumn{4}{|c|}{ Echocardiographic parameters } \\
\hline LVDd (mm) & $46.6 \pm 3.5$ & $64.4 \pm 10.3$ & $<0.0001$ \\
\hline LVDs (mm) & $29.1 \pm 4.7$ & $54.7 \pm 11.4$ & $<0.0001$ \\
\hline LVEF (\%) & $63.9 \pm 6.1$ & $29.8 \pm 8.4$ & $<0.0001$ \\
\hline $\mathrm{E} / \mathrm{A}$ & $0.89 \pm 0.24$ & $1.79 \pm 1.30$ & 0.030 \\
\hline $\mathrm{DT}(\mathrm{ms})$ & $229.4 \pm 57.6$ & $179.3 \pm 62.5$ & 0.030 \\
\hline$E / e^{\prime}$ & $8.2 \pm 2.1$ & $13.1 \pm 4.0$ & $<0.001$ \\
\hline MR/LA area & - & $0.39 \pm 0.19$ & - \\
\hline LV mass index $\left(\mathrm{g} / \mathrm{m}^{2}\right)$ & $102.1 \pm 19.0$ & $159.7 \pm 39.5$ & $<0.0001$ \\
\hline Sphericity index & $0.55 \pm 0.05$ & $0.78 \pm 0.11$ & $<0.0001$ \\
\hline Log plasma BNP & $1.32 \pm 0.16$ & $2.67 \pm 0.09$ & $<0.0001$ \\
\hline
\end{tabular}

All values are expressed as mean \pm SD. $P$ value of 0.05 was considered significant.

BNP, brain-type natriuretic peptide; DT, deceleration time; E/A, ratio between early and late diastolic transmitral flow velocity; E/e', the ratio of maximal early diastolic filling wave velocity to maximal early diastolic myocardial velocity; HF, heart failure; LA, left atrial; LV, left ventricular; LVDd, left ventricular end-diastolic dimension; LVDs, left ventricular end-systolic dimension; LVEF, left ventricular ejection fraction; MR, mitral regurgitation.

\begin{tabular}{|c|c|c|c|c|c|c|}
\hline & \multicolumn{3}{|c|}{ Control $(n=11)$} & \multicolumn{3}{|c|}{ HF $(n=34)$} \\
\hline & Before ASV & During ASV & $P$ value & Before ASV & During ASV & $P$ value \\
\hline Heart rate (beats/min) & $65.7 \pm 10.1$ & $65.0 \pm 9.3$ & 0.420 & $70.7 \pm 13.9$ & $69.9 \pm 13.8$ & 0.357 \\
\hline Systolic BP (mmHg) & $143.8 \pm 27.8$ & $138.8 \pm 24.7$ & 0.339 & $110.1 \pm 26.4$ & $107.7 \pm 22.6$ & 0.069 \\
\hline PCWP (mmHg) & $8.4 \pm 2.1$ & $9.3 \pm 1.9$ & 0.185 & $15.7 \pm 8.2$ & $16.3 \pm 7.9$ & 0.390 \\
\hline PASP (mmHg) & $25.2 \pm 4.4$ & $25.5 \pm 6.3$ & 0.747 & $37.4 \pm 12.9$ & $36.4 \pm 12.1$ & 0.240 \\
\hline $\operatorname{RAP}(\mathrm{mmHg})$ & $5.3 \pm 3.3$ & $6.9 \pm 2.8$ & 0.023 & $6.2 \pm 5.4$ & $8.2 \pm 4.6$ & $<0.001$ \\
\hline SVRI (dyne $\left.{ }^{*} \mathrm{~s}^{*} \mathrm{~cm}^{-5 *} \mathrm{~m}^{-2}\right)$ & $2,448 \pm 598$ & $2,919 \pm 765$ & $<0.001$ & $2,581 \pm 602$ & $2,663 \pm 758$ & 0.416 \\
\hline PVRI (dyne $\left.{ }^{*} \mathrm{~s}^{*} \mathrm{~cm}^{-5 *} \mathrm{~m}^{-2}\right)$ & $163 \pm 80$ & $245 \pm 138$ & 0.078 & $286.9 \pm 167.0$ & $253.0 \pm 102.3$ & 0.151 \\
\hline
\end{tabular}

All values are expressed as mean $\pm S D$. $P$ value of 0.05 was considered significant.

ASV, adaptive servo-ventilation; BP, blood pressure; HF, heart failure; PCWP, pulmonary capillary wedge pressure;

PASP, pulmonary artery systolic pressure; PVRI, pulmonary vascular resistance index; RAP, right atrial pressure;

SVRI, systemic vascular resistance index.

breathing effort, and reducing LV preload and afterload. ${ }^{14-20}$ In stable HF patients, CPAP has been demonstrated to increase cardiac output $(\mathrm{CO})$ and stroke volume $(\mathrm{SV})$ in patients with higher pulmonary capillary wedge pressure (PCWP) in the setting of low-level $\left(5 \mathrm{cmH}_{2} \mathrm{O}\right) \mathrm{CPAP},{ }^{17}$ and bilevel NPPV to increase $\mathrm{CO}$ in patients with PCWP $>12 \mathrm{mmHg} .{ }^{19}$ However, the effects of ASV on the hemodynamics in patients with $\mathrm{HF}$ have not been determined. We aimed to compare HF patients with spherical and dilated hearts with control subjects who had normal heart structure in order to determine the relationship between LV structure and function and the acute response of SV to ASV in HF patients receiving optimal medical therapy. We also aimed to identify the predictors for acute favorable effects of ASV in these patients.

\section{Methods}

\section{Patients}

The present study included 34 patients with chronic stable HF, and 11 control patients who underwent right cardiac catheterization between April 2009 and July 2011 in Hokkaido University Hospital. HF was defined as New York Heart Asso- ciation (NYHA) functional class II or III, LVEF $<45 \%$ on echocardiography, and plasma BNP $>100 \mathrm{pg} / \mathrm{ml}$. Patients with severe pulmonary, neurological or muscular disease, and intolerance of ASV were excluded. For the HF patients, this study was performed after stabilization of HF symptoms. Control patients were suspected to have coronary artery disease, but diagnosed as having no significant organic stenosis by coronary angiography and no evidence of structural heart diseases.

This study was prospective in design. We enrolled 11 consecutive control and $34 \mathrm{HF}$ patients. We hypothesized the effect size to be 0.53 based on a previous study. ${ }^{17}$ Under the conditions of 2-sided significance level of $5 \%$ and $80 \%$ of power, a sample size of $30 \mathrm{HF}$ patients was required.

The study was approved by the Ethics Committee of Hokkaido University Hospital. All patients gave written informed consent.

\section{Study Protocol}

The hemodynamic measurements [PCWP, pulmonary artery pressure, right atrial pressure (RAP), cardiac index, SV index (SVI), systemic vascular resistance index, and pulmonary vascular resistance index] were performed through a femoral vein 

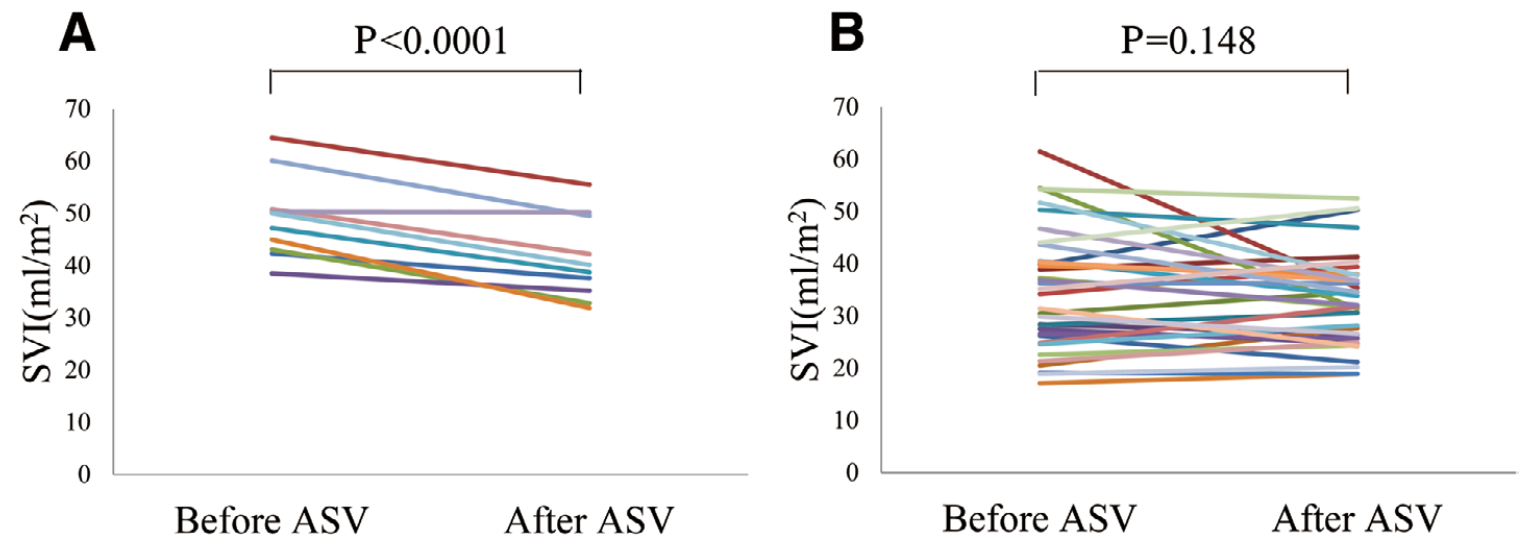

Figure 1. Changes in stroke volume index (SVI) before and during adaptive servo-ventilation (ASV) in control $(\mathbf{A}, \mathrm{n}=11)$ and heart failure $(B, n=34)$ patients.

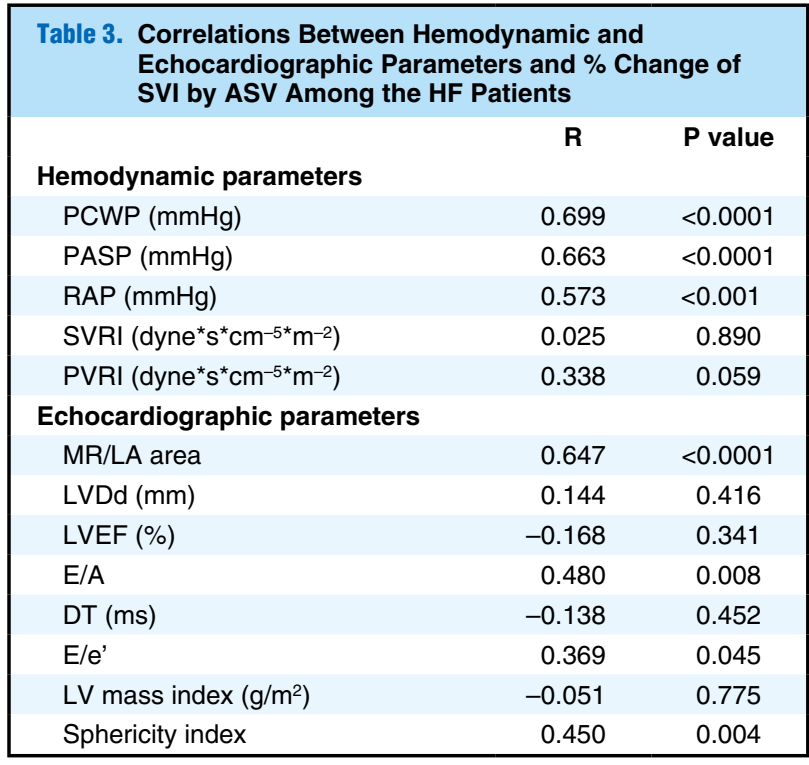

$P$ value of 0.05 was considered significant. Abbreviations as in Tables 1,2.

using a 7Fr Swan-Ganz catheter (Edwards Lifesciences, CA, USA) with the patient awake. $\mathrm{CO}$ was determined by thermodilution. Pressure recordings and $\mathrm{CO}$ measurement were performed at baseline and after $15 \mathrm{~min}$ of ASV. ASV (Auto Set CS; Teijin Pharma, Tokyo, Japan) was used without oxygenation and with a fitted nasal mask (Teijin Pharma) in the default mode: EPAP at $5 \mathrm{cmH}_{2} \mathrm{O}$, and IPAP at $3-10 \mathrm{cmH}_{2} \mathrm{O}$. Recordings were performed at deepest expiration within $20 \mathrm{~s}$ without holding the breath.

LV structure and function were assessed by simultaneous echocardiography at baseline: LV end-diastolic dimension (LVDd), LV end-systolic dimension (LVDs), LVEF, interventricular septal thickness (IVS), LV posterior wall thickness (LVPW), the ratio between early and late diastolic transmitral flow velocity (E/A), the ratio of maximal early diastolic filling wave velocity to maximal early diastolic myocardial velocity
(E/e'), and deceleration time (DT). LVEF was measured from the apical 4- and 2-chamber images using the biplane method of disks. The sphericity index, an index of LV structural remodeling, was calculated as the ratio between the short-axis and long-axis dimensions of the LV (from the apex to the mitral valve annular plane) in the apical 4-chamber view. ${ }^{21}$ The mitral regurgitation (MR) area/left atrial (LA) area was calculated from the apical 4-chamber view during the systolic phase. LV mass was calculated according to the following formula: ${ }^{22}$

$$
\begin{aligned}
\mathrm{LV} \text { mass }= & 0.8 \times\left\{1.04\left[(\mathrm{LVDd}+\mathrm{LVPW}+\mathrm{IVS})^{3}-(\mathrm{LVDd})^{3}\right]\right\}+ \\
& 0.6 \mathrm{~g} .
\end{aligned}
$$

Plasma BNP was measured in all study patients.

The response to ASV was assessed by changes in the SVI. Acute response was defined as an increase in SVI during ASV, and non-response was any reduction or no change in the SVI. We compared the hemodynamic changes between the control and HF patients, and identified the predictors of an acute response of the SVI to ASV in HF patients.

\section{Statistical Analysis}

Continuous variables are shown as mean \pm SD. Hemodynamic parameters at baseline and after ASV were compared by paired t-test. The Pearson correlation coefficient between \% change of SVI and each continuous variable was calculated. Multivariable analysis was also conducted. To compare each parameter between the control and $\mathrm{HF}$ groups, or between responders and non-responders, we used an unpaired t test or Fisher's exact test for categorical variables. We used receiveroperating characteristic (ROC) curves to identify the parameters for detecting responders to ASV. For all tests, 2-sided $\mathrm{P}<0.05$ was considered statistically significant, and all analyses were performed by JMP 9.0 (SAS Institute, Cary, NC, USA).

\section{Results}

\section{Patients' Characteristics}

The causes of HF were ischemic cardiomyopathy in 14 patients $(41 \%)$, dilated cardiomyopathy in $10(29 \%)$, chronic myocarditis in $5(15 \%)$, dilated hypertrophic cardiomyopathy in 3 
A

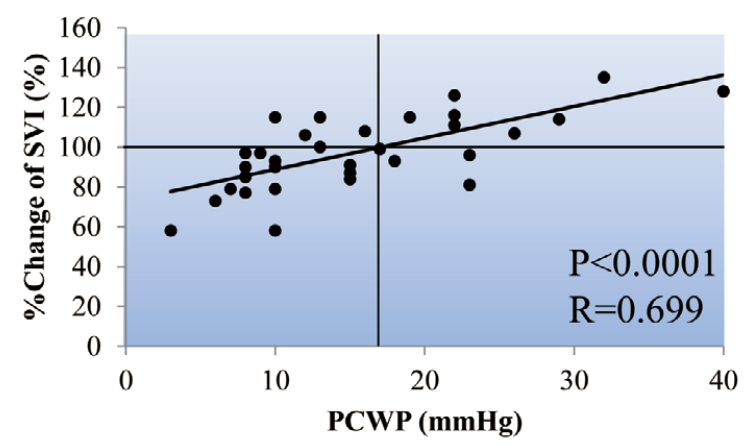

C

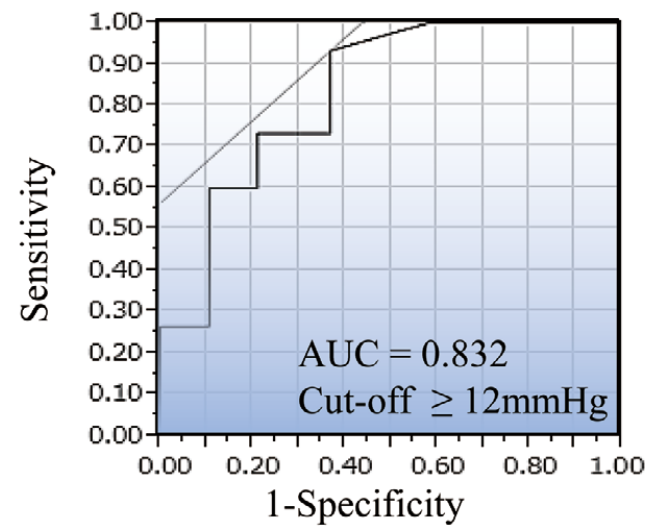

B

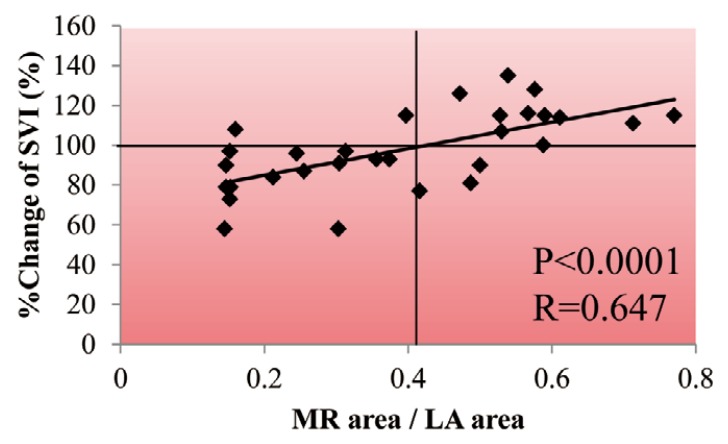

D

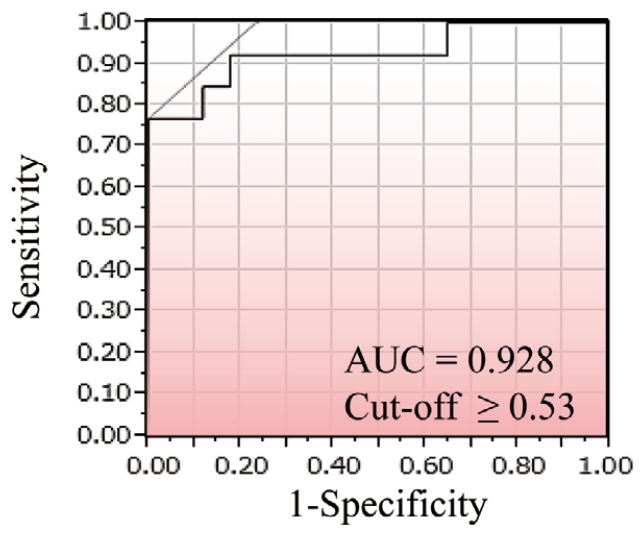

Figure 2. Correlation between \%change of stroke volume index (SVI) and pulmonary capillary wedge pressure (PCWP, A) or mitral regurgitation (MR) area/left atrial (LA) area (B). Receiver-operating characteristic curve analysis of PCWP (C) or MR area/ LA area (D) for an increase in SVI. AUC, area under the curve.

\begin{tabular}{|lccc|}
\hline \multicolumn{2}{|c|}{$\begin{array}{l}\text { Table 4. Multivariate Analysis Between Hemodynamic and Echocardiographic Parameters and \% Change of } \\
\text { SVI Among the HF Patients }\end{array}$} & \multicolumn{3}{c}{ 95\% Cl } & P value \\
& Regression coefficient & 0.05 to 62.95 & 0.044 \\
PCWP (mmHg) & 0.667 & -1.89 to 60.46 & 0.213 \\
PASP $(\mathrm{mmHg})$ & -0.437 & -1.29 to 62.39 & 0.533 \\
RAP $(\mathrm{mmHg})$ & 0.152 & 20.1 to 694.4 & 0.005 \\
MR/LA area & 0.527 & -6.15 to 68.46 & 0.741 \\
E/A & 0.074 & -1.18 to 61.91 & 0.621 \\
E/e' & 0.080 & -61.5 to 66.6 & 0.933 \\
Sphericity index & 0.013 &
\end{tabular}

$P$ value of 0.05 was considered significant. $\mathrm{Cl}$, confidence interval. Other abbreviations as in Tables 1,2.

(9\%), and others in $2(6 \%)$. In total, $23(68 \%)$ patients were in sinus rhythm, 6 (18\%) had biventricular pacing, $3(9 \%)$ had atrial fibrillation, and $2(6 \%)$ had pacing rhythm. NYHA functional class was II in $13(38 \%)$ and III in $21(62 \%)$ patients. Medical treatment induced diuretics in $28(82 \%)$, angiotensinconverting enzyme inhibitors or angiotensin II receptor blockers in $30(88 \%)$, and $\beta$-blockers in $32(94 \%)$ patients.

The baseline demographic and echocardiographic characteristics of the control and HF groups are summarized in Table 1. Age and sex were comparable between groups. Log plasma BNP was $1.32 \pm 0.16$ in the control and $2.67 \pm 0.09$ in the HF group $(\mathrm{P}<0.0001)$. MR/LA area was $0.39 \pm 0.19$ in the HF group. As expected, LVDd, LVDs, E/A, E/e', LV mass index, and sphericity index were significantly higher, and LVEF and DT were lower, in HF patients than in controls.

\section{Effects of ASV on Hemodynamics}

All patients were awake and did not have apnea or hypopnea during the study. Therefore, the beneficial effects of ASV on hemodynamics were not via alleviation of SDB (Table 2, 


\begin{tabular}{|c|c|c|c|}
\hline & Responder $(n=15)$ & Non-responder $(n=19)$ & $P$ value \\
\hline Age (years) & $52.9 \pm 17.5$ & $60.7 \pm 10.8$ & 0.117 \\
\hline Gender (F/M) & $2 / 13$ & $6 / 13$ & 0.213 \\
\hline \multicolumn{4}{|l|}{ Hemodynamic parameters } \\
\hline Heart rate (beats/min) & $74.7 \pm 12.6$ & $67.4 \pm 13.9$ & 0.130 \\
\hline Systolic BP (mmHg) & $101.7 \pm 22.5$ & $117.1 \pm 27.9$ & 0.095 \\
\hline PCWP (mmHg) & $20.7 \pm 8.3$ & $11.7 \pm 5.6$ & $<0.001$ \\
\hline PASP $(\mathrm{mmHg})$ & $45.7 \pm 14.7$ & $30.8 \pm 5.7$ & $<0.001$ \\
\hline RAP $(\mathrm{mmHg})$ & $9.5 \pm 5.9$ & $3.6 \pm 3.3$ & $<0.001$ \\
\hline SVRI (dyne* $\left.\mathrm{s}^{*} \mathrm{~cm}^{-5 *} \mathrm{~m}^{-2}\right)$ & $2,566 \pm 626$ & $2,594 \pm 600$ & 0.897 \\
\hline PVRI (dyne* $\left.\mathrm{s}^{*} \mathrm{~cm}^{-5 *} \mathrm{~m}^{-2}\right)$ & $286.5 \pm 131.3$ & $218.9 \pm 93.6$ & 0.116 \\
\hline \multicolumn{4}{|c|}{ Echocardiographic parameters } \\
\hline MR/LA area & $0.542 \pm 0.148$ & $0.274 \pm 0.121$ & $<0.0001$ \\
\hline LVDd (mm) & $67.3 \pm 11.7$ & $62.1 \pm 8.5$ & 0.143 \\
\hline $\operatorname{LVEF}(\%)$ & $28.6 \pm 9.59$ & $30.7 \pm 7.4$ & 0.469 \\
\hline$E / A$ & $2.27 \pm 1.24$ & $1.49 \pm 1.27$ & 0.116 \\
\hline DT (ms) & $177.1 \pm 76.1$ & $181.1 \pm 51.9$ & 0.862 \\
\hline$E / e^{\prime}$ & $13.9 \pm 3.8$ & $12.5 \pm 4.2$ & 0.371 \\
\hline LV mass index $\left(\mathrm{g} / \mathrm{m}^{2}\right)$ & $164.3 \pm 42.0$ & $156.0 \pm 38.1$ & 0.550 \\
\hline Sphericity index & $0.82 \pm 0.08$ & $0.74 \pm 0.11$ & 0.025 \\
\hline Log plasma BNP & $2.89 \pm 0.55$ & $2.49 \pm 0.49$ & 0.032 \\
\hline
\end{tabular}

All values are expressed as mean $\pm S D$. $P$ values are for comparison of responders and non-responders at baseline. $P$ value of 0.05 was considered significant. Abbreviations as in Tables 1,2.

\begin{tabular}{|c|c|c|c|}
\hline \multicolumn{4}{|c|}{$\begin{array}{l}\text { Table 6. Areas Under the ROC Curves for Predicting } \\
\text { Response to ASV Among the HF Patients }\end{array}$} \\
\hline & AUC & $P$ value & $\begin{array}{l}\text { Cut-off } \\
\text { value }\end{array}$ \\
\hline PCWP (mmHg) & 0.832 & 0.006 & $\geq 12$ \\
\hline PASP $(\mathrm{mmHg})$ & 0.832 & 0.006 & $\geq 36$ \\
\hline $\mathrm{RAP}(\mathrm{mmHg})$ & 0.819 & 0.010 & $\geq 6$ \\
\hline MR/LA area & 0.928 & 0.003 & $\geq 0.53$ \\
\hline$E / A$ & 0.707 & 0.121 & $\geq 1.18$ \\
\hline$E / e^{\prime}$ & 0.588 & 0.360 & $\geq 13.4$ \\
\hline Sphericity index & 0.711 & 0.037 & $\geq 0.71$ \\
\hline
\end{tabular}

$P$ values are for AUCs vs. the null hypothesis of a true area of 0.5 . AUC, area under the curve; ROC, receiver-operating characteristic. Other abbreviations as in Tables 1,2.

Figure 1). Heart rate, systolic blood pressure, and PCWP, did not change during ASV in either group.

SVI significantly decreased from $49.3 \pm 7.6$ to $41.3 \pm 7.6 \mathrm{ml} / \mathrm{m}^{2}$ $(\mathrm{P}<0.0001)$ in the control group. In contrast, it did not change overall in the $\mathrm{HF}$ group $\left(34.8 \pm 11.5\right.$ vs. $32.8 \pm 8.9 \mathrm{ml} / \mathrm{m}^{2}$, $\mathrm{P}=0.148$ ), with variable changes including an increase in 15 and a decrease in 19 patients (Figure 1).

\section{Correlations Between Hemodynamic and Echocardiographic Parameters and Changes in SVI}

The correlation coefficients between the baseline parameters and \% change of SVI during ASV in HF patients are shown in Table 3 and Figure 2. Linear regression analyses showed that the \% change of SVI significantly correlated with PCWP ( $\mathrm{R}=0.699, \mathrm{P}<0.0001)$, PASP $(\mathrm{R}=0.633, \mathrm{P}<0.0001), \mathrm{RAP}$ $(\mathrm{R}=0.573, \mathrm{P}<0.001), \mathrm{MR} / \mathrm{LA}$ area $(\mathrm{R}=0.647, \mathrm{P}<0.0001), \mathrm{E} / \mathrm{A}$ $(\mathrm{R}=0.480, \mathrm{P}=0.008), \mathrm{E} / \mathrm{e}^{\prime}(\mathrm{R}=0.369, \mathrm{P}=0.045)$, and sphericity index $(\mathrm{R}=0.450, \mathrm{P}=0.004)$. We performed multivariate analysis for the 7 variables that significantly correlated with $\%$ change of SVI by linear regression analysis. PCWP and MR/LA area were independent predictive factors for identifying a $\%$ change of SVI (Table 4).

\section{Comparison Between Responders and Non-Responders}

Among the $34 \mathrm{HF}$ patients, 15 (44\%) were responders and 19 $(56 \%)$ were non-responders. Table 5 compares the demographic, hemodynamic, and echocardiographic parameters of the responders and non-responders. Responders had higher PCWP, PASP, and RAP, greater MR, higher sphericity index, and higher plasma BNP level.

To identify the predictors for responders, we performed ROC analysis for the 7 variables that significantly correlated with \% change of SVI by linear regression analysis. PCWP ( $\geq 12 \mathrm{mmHg}$ ), PASP ( $\geq 36 \mathrm{mmHg}$ ), RAP ( $\geq 6 \mathrm{mmHg}$ ), MR/LA area $(\geq 0.53)$, and sphericity index $(\geq 0.71)$ were identified as significant predictors for responders (Table 6, Figure 2).

\section{Discussion}

The present study demonstrated that ASV reduced SVI in the control patients, which is consistent with previous studies that found positive end-expiratory pressure (PEEP) or CPAP reduced SV in the normal heart. ${ }^{12,18,23-25}$ In the normal heart, SV is largely dependent on preload, ${ }^{26}$ and thus ASV can reduce the SVI by decreasing LV filling according to the FrankStarling mechanism. ${ }^{24}$ The decrease in LV filling results from the elevation in intrathoracic pressure by CPAP or ASV.

In contrast, the HF patients showed either increased or decreased SVI during ASV. We demonstrated that higher PCWP and greater MR were independent predictors, and a more spherical heart shape might also predict acute beneficial effects of ASV on the hemodynamics in HF patients. The increase in SVI in HF patients with high PCWP by ASV is consistent with previous observations during CPAP ${ }^{17,19,27}$ and bilevel NPPV. ${ }^{19}$ Interestingly, the present study demonstrated that both MR 
and the sphericity index could predict acute hemodynamic improvement by ASV, consistent with the study by Bellone et al in which the use of $30 \mathrm{~min}$ of CPAP and bilevel NPPV significantly reduced MR in HF patients. ${ }^{28}$ Functional MR is a common finding in patients with severe chronic HF, and is closely associated with distortion of the mitral valve annulus secondary to leaflet tethering because of the outward displacement of the papillary muscles by LV remodeling or dilatation. ${ }^{29}$ Positive-pressure ventilation can reduce LV volume by decreasing preload. Therefore, ASV can reduce preload, improve functional MR by changing the morphology of the heart, and increase the SVI in patients with severe HF.

ASV can also decrease afterload by several mechanisms. First, it can increase the cardiac surface pressure by positive airway pressure, which can lead to a decrease in LV transmural pressure. ${ }^{24}$ Second, the appropriate and regular movement of the lungs controlled by ASV can inhibit sympathetic nerve activity and inversely activate vagal nerve activity. ${ }^{30}$ As a result, systemic vascular resistance can decrease through expansion of the peripheral artery, and thus reduce afterload. In the severely failing heart, $\mathrm{SV}$ is more responsive to changes in afterload than in preload. ${ }^{26}$ In summary, a reduction in both preload and afterload could decrease functional MR and ameliorate LV structural remodeling, and thus result in favorable homodynamic effects, reflected in an increased SVI.

The sphericity index is a most important indicator of the beneficial effect on hemodynamics by ASV. ASV may change the LV shape from spherical to oval by reducing both preload and afterload, and by directly pushing down the diaphragm with the positive pressure from lung inflation. This reverse remodeling caused by ASV might also be involved in the improvement of hemodynamics in HF patients.

ASV was originally designed to treat CSR by regulating the unstable breathing pattern in patients with SDB. The present study demonstrated that ASV might also have direct beneficial effects on the hemodynamics in HF patients by reducing preload and afterload via a different mechanism. These findings are supported by previous studies in which the efficacy of ASV was recognized regardless of the severity of SDB. ${ }^{12,13}$

\section{Study Limitations}

First, we could not provide direct evidence that the severity of MR or LV remodeling was improved by ASV because the evaluation of LV structure or function by echocardiography was performed only at baseline, and its quantitative assessment is difficult by cardiac catheterization. Therefore, this important point needs to be confirmed using other noninvasive methods such as echocardiography or cardiac magnetic resonance imaging. Second, ASV has favorable effects on hemodynamics through both PEEP and pressure support, so it needs to be determined whether the SVI in the end-expiratory phase differs from that in the end-inspiratory phase. However, it was impossible to measure SVI separately in the expiratory and inspiratory phases by the thermodilution method or the Fick principle. Third, we could not compare the hemodynamic effects of ASV with those of other NPPV, including CPAP. We need to perform further examinations in HF patients of whether ASV exerts a better effect than other NPPV with regard to hemodynamic efficacy. Fourth, the study subjects were not asleep during the study, indicating that ASV might have direct beneficial effects on hemodynamics not via alleviation of SDB. Therefore, further studies are needed to determine whether the present findings can be extrapolated to HF patients who are asleep. Fifth, we enrolled only stable HF patients and did not study those with acutely decompensated HF because of rap- idly increasing RA pressure by central volume shift and in whom ASV may also be beneficial. The effects of ASV on hemodynamics in the stable state may be different from those in the acutely decompensated state. Finally, this study was designed to assess the acute hemodynamic effects of ASV and not to examine these effects as a chronic treatment. Therefore, it needs to be determined whether a responder in the acute phase has similar benefit in the chronic phase.

In conclusion, the present study demonstrated that the severity of MR and the sphericity index, well as PCWP, could predict acute favorable effects on hemodynamics by ASV in HF patients. These findings could be helpful for identifying HF patients who might benefit from ASV therapy.

\section{Acknowledgment}

This study was supported in part by grants from the Ministry of Education, Culture, Sports, Science \& Technology (23591024).

\section{References}

1. Oldenburg O, Lamp B, Faber L, Teschler H, Horstkotte D, Topfer V. Sleep-disordered breathing in patients with symptomatic heart failure: A contemporary study of prevalence in and characteristics of 700 patients. Eur J Heart Fail 2007; 9: 251-257.

2. Sin DD, Logan AG, Fitzgerald FS, Liu PP, Bradley TD. Effects of continuous positive airway pressure on cardiovascular outcomes in heart failure patients with and without Cheyne-Stokes respiration. Circulation 2000; 102: 61-66.

3. Kasai T, Narui K, Dohi T, Takaya H, Yanagisawa N, Dungan G, et al. First experience of using new adaptive servo-ventilation device for Cheyne-Stokes respiration with central sleep apnea among Japanese patients with congestive heart failure: Report of 4 clinical cases. Circ J 2006; 70: $1148-1154$.

4. Arzt M, Wensel R, Montalvan S, Schichtl T, Schroll S, Budweiser S, et al. Effects of dynamic bilevel positive airway pressure support on central sleep apnea in men with heart failure. Chest 2008; 134: $61-$ 66.

5. Philippe C, Stoica-Herman M, Drouot X, Raffestin B, Escourrou P, Hittinger $\mathrm{L}$, et al. Compliance with and effectiveness of adaptive servoventilation versus continuous positive airway pressure in the treatment of Cheyne-Stokes respiration in heart failure over a six month period. Heart 2006; 92: 337-342.

6. Koyama T, Watanabe H, Kobukai Y, Makabe S, Munehisa Y, Ino K, et al. Beneficial effects of adaptive servo-ventilation in patients with chronic heart failure. Circ J 2010; 74: 2118-2124.

7. Oldenburg O, Schmidt A, Lamp B, Bitter T, Muntean BG, Langer C, et al. Adaptive servoventilation improves cardiac function in patients with chronic heart failure and Cheyne-Stokes respiration. Eur J Heart Fail 2008; 10: 581-586.

8. Pepperell JC, Maskell NA, Jones DR, Langford-Wiley BA, Crosthwaite N, Stradling JR, et al. A randomized controlled trial of adaptive ventilation for Cheyne-Stokes breathing in heart failure. Am J Respir Crit Care Med 2003; 168: 1109-1114.

9. Kasai T, Usui Y, Yoshioka T, Yanagisawa N, Takata Y, Narui K, et al. Effect of flow-triggered adaptive servo-ventilation compared with continuous positive airway pressure in patients with chronic heart failure with coexisting obstructive sleep apnea and Cheyne-Stokes respiration. Circ Heart Fail 2010; 3: 140-148.

10. Teschler H, Dohring J, Wang YM, Berthon-Jones M. Adaptive pressure support servo-ventilation: A novel treatment for Cheyne-Stokes respiration in heart failure. Am J Respir Crit Care Med 2001; 164: 614-619.

11. Harada D, Joho S, Oda Y, Hirai T, Asanoi H, Inoue H. Short term effect of adaptive servo-ventilation on muscle sympathetic nerve activity in patients with heart failure. Auton Neurosci 2011; 161: 95-102.

12. Takama N, Kurabayashi M. Effectiveness of adaptive servo-ventilation for treating heart failure regardless of the severity of sleep-disordered breathing. Circ J 2011; 75: 1164-1169.

13. Koyama T, Watanabe $\mathrm{H}$, Igarashi $\mathrm{G}$, Terada S, Makabe S, Ito H. Short-term prognosis of adaptive servo-ventilation therapy in patients with heart failure. Circ J 2011; 75: 710-712.

14. Pang D, Keenan SP, Cook DJ, Sibbald WJ. The effect of positive pressure airway support on mortality and the need for intubation in cardiogenic pulmonary edema: A systematic review. Chest 1998; 114: $1185-1192$. 
15. Buda AJ, Pinsky MR, Ingels NB, Daughters GT, Stinson EB, Alderman EL. Effect of intrathoracic pressure on left ventricular performance. N Engl J Med 1979; 301: 453-459.

16. Lenique F, Habis M, Lofaso F, Dubois-Rande JL, Harf A, Brochard L. Ventilatory and hemodynamic effects of continuous positive airway pressure in left heart failure. Am J Respir Crit Care Med 1997; 155: 500-505.

17. Bradley TD, Holloway RM, McLaughlin PR, Ross BL, Walters J, Liu PP. Cardiac output response to continuous positive airway pressure in congestive heart failure. Am Rev Respir Dis 1992; 145: 377-382.

18. Naughton MT, Rahman MA, Hara K, Floras JS, Bradley TD. Effect of continuous positive airway pressure on intrathoracic and left ventricular transmural pressures in patients with congestive heart failure. Circulation 1995; 91: 1725-1731.

19. Philip-Joet FF, Paganelli FF, Dutau HL, Saadjian AY. Hemodynamic effects of bilevel nasal positive airway pressure ventilation in patients with heart failure. Respiration 1999; 66: 136-143.

20. Park M, Sangean MC, Volpe Mde S, Feltrim MI, Nozawa E, Leite $\mathrm{PF}$, et al. Randomized, prospective trial of oxygen, continuous positive airway pressure, and bilevel positive airway pressure by face mask in acute cardiogenic pulmonary edema. Crit Care Med 2004; 32: $2407-2415$.

21. D'Cruz IA, Shroff SG, Janicki JS, Jain A, Reddy HK, Lakier JB. Differences in the shape of the normal, cardiomyopathic, and volume overloaded human left ventricle. J Am Soc Echocardiogr 1989; 2: $408-414$.

22. Lang RM, Bierig M, Devereux RB, Flachskampf FA, Foster E, Pellikka PA, et al. Recommendations for chamber quantification: A report from the American Society of Echocardiography's Guidelines and Standards Committee and the Chamber Quantification Writing
Group, developed in conjunction with the European Association of Echocardiography, a branch of the European Society of Cardiology. $J$ Am Soc Echocardiogr 2005; 18: 1440-1463.

23. Fewell JE, Abendschein DR, Carlson CJ, Murray JF, Rapaport E. Continuous positive-pressure ventilation decreases right and left ventricular end-diastolic volumes in the dog. Circ Res 1980; 46: 125132.

24. Johnston WE, Vinten-Johansen J, Santamore WP, Case LD, Little WC. Mechanism of reduced cardiac output during positive end-expiratory pressure in the dog. Am Rev Respir Dis 1989; 140: 1257 1264.

25. Innes JA, De Cort SC, Kox W, Guz A. Within-breath modulation of left ventricular function during normal breathing and positive-pressure ventilation in man. J Physiol 1993; 460: 487-502.

26. Pinsky MR, Matuschak GM, Klain M. Determinants of cardiac augmentation by elevations in intrathoracic pressure. J Appl Physiol 1985; 58: $1189-1198$.

27. Steiner S, Schannwell CM, Strauer BE. Left ventricular response to continuous positive airway pressure: Role of left ventricular geometry. Respiration 2008; 76: 393-397.

28. Bellone A, Barbieri A, Ricci C, Iori E, Donateo M, Massobrio M, et al. Acute effects of non-invasive ventilatory support on functional mitral regurgitation in patients with exacerbation of congestive heart failure. Intensive Care Med 2002; 28: 1348-1350.

29. Otsuji Y, Levine RA, Takeuchi M, Sakata R, Tei C. Mechanism of ischemic mitral regurgitation. J Cardiol 2008; 51: 145-156.

30. Seals DR, Suwarno NO, Dempsey JA. Influence of lung volume on sympathetic nerve discharge in normal humans. Circ Res 1990; 67: $130-141$. 